American Medical Journal 3 (2): 130-140, 2012

ISSN 1949-0070

(C) 2012 Science Publications

\title{
Platelets, Coagulation and Cancer: Multifaceted Interactions
}

\author{
${ }^{1}$ H.A. Goubran and ${ }^{2}$ T. Burnouf \\ ${ }^{1}$ Saskatoon Cancer Centre and College of Medicine, University of Saskatchewan, Canada \\ ${ }^{2}$ Human Protein Process Sciences (HPPS)-Lille, France
}

\begin{abstract}
Approach: Literature review of the multifaceted interactions between platelets, coagulation and cancer. Results: Over the years, the links existing between cancer development, progression and occurrence of metastasis on one side and coagulation on the other have become obvious. Tumors seems to activate platelets whereas, platelets, on the other hand, through their capacity to activate and release soluble factors and microparticles, interact with tumor cells and influence immune regulation. They appear to be key regulators of many cancer events. Furthermore, coagulation with its different facets also interplays and significantly crosstalks with malignancy. The objectives of this article are to review the mechanisms through which cancer interacts with platelets and the coagulation, triggering thrombosis and the role played by platelets and coagulation factors in the regulation of cancer and to underline the perspectives that are now open in the development of novel diagnostic tools and new cancer treatment strategies. Conclusion/Recommendations: Challenging issues and unresolved questions still need to be addressed to understand the complexity existing between coagulation factors and platelet components and the different stages of cancer progression. Recent discoveries are leading clinicians to consider new therapeutic applications of anticoagulant therapies or new drugs targeting specific platelet functions in cancer patients' management. Furthermore, markers of coagulation and platelet activity may prove to serve as biomarkers for dormant tumors.
\end{abstract}

Key words: Cancer, thromboses, coagulation, platelets and metastasis

\section{INTRODUCTION}

The objectives of this article are to review the mechanisms through which cancer interacts with platelets and the coagulation, triggering thrombosis and the role played by platelet and coagulation factors in the regulation of cancer and to underline the new perspectives that are now open in the development of novel diagnostic tools and new cancer treatment strategies.

I-Clinical facts: venous thromboembolism manifestations in cancer: The most clearly established relationship existing between coagulation and cancer is evidenced by the frequent complication of Venous Thromboembolism (VTE) in cancer patients. Indeed, VTE may represent its first clinical manifestation, often antedating any clinically objective sign of the malignancy itself (Baron et al., 1998; Sorensen et al., 1998). Migratory superficial thrombophlebitis was first described by Trousseau (1865) as forewarning of an occult visceral malignancy and his sign, known as "Trousseau's syndrome", is almost synonymous to occult malignancy (Varki, 2007). Ironically, he reported a similar finding in himself, when he developed a Corresponding Author: Goubran, H.A., Saskatoon Cancer Centre and College of Medicine, University of Saskatchewan, Canada gastric cancer two years later. Greenwell (1991) and Sack et al. (1977) extended the term Trousseau's syndrome to include chronic disseminated intravascular coagulopathy associated with microangiopathy, verrucous endocarditisand arterial emboli in patients with cancer, often occurring in the context of makingpositive carcinomas. In recent times, the term has been ascribed to any kind of coagulopathy occurring in the setting of any type of malignancy (Varki, 2007).

There is a statistically significant and clinically important association between idiopathic venous thrombosis and the subsequent development of clinically overt cancer, especially among patients in whom VTE recurs during follow-up. About $10 \%$ of patients presenting with unprovoked - idiopathic thrombosis are diagnosed with cancer within a few years (Prandoni et al., 1992). Even more, during the first year, the incidence of cancer in these patients is as high as 2.1-4.6\%, (Baron et al., 1998; Sorensen et al., 1998; Prandoni et al., 1992) with an incidence at its peak within the first 6 months (Nordstrom et al., 1994). Approximately $40 \%$ of those cases are already presenting metastasis at the time of diagnosis (Baron et al., 1998; Sorensen et al., 1998; Nordstrom et al., 1994). Cancer diagnosed at the same time as or within 
one year after an episode of VTE is associated with an advanced stage and a poor prognosis (Sorensen et al., 2000). Epidemiological estimates show that the annual incidence of VTE in cancer patients may be as much as $1: 200 /$ year compared to $\approx 70-113$ cases/100,000/year in the general population (Silverstein et al., 1998). A large Dutch population-based case control study of 3220 patients found that the Overall Risk (OR) of VTE was significantly increased in patients with malignancy (adjusted OR 6.7) and even more so in patients with metastasis (adjusted OR 19.8) (Blom et al., 2005). The highest risk was observed in patients with lung cancer (Odds Ratio (OR): 22.2), hematological malignancies (OR: 28.0) and gastrointestinal cancer (OR: 20.3) (Blom et al., 2005). There was a moderately increased risk in patient's ovarian cancer (OR: 3.1; 95\%CI: 0.6-15.3) and prostate cancer (OR: 2.2; 95\%CI: 0.9-5.4). The risk is enhanced by anticancer therapy, such as surgery and chemotherapy.

Thrombocytosis could reflect inflammation but is considered by some as a paraneoplastic phenomenon (Estrov et al., 1995). Its presence warrants thorough investigation for the presence of severe underlying disease, most complicated pyogenic infections, inflammatory rheumatic diseases and malignancy. Moreover, thrombocytosis is a marker for major complications and is an independent predictor of mortality in hospitalized patients for non-malignant as well as malignant conditions (Tchebiner et al., 2011).

The evidence of a relationship between cancer and VTE was, understandably, used to attempt to develop diagnostics tools. Many screening strategies to identify occult or overt malignancies including testing for tumor markers and advanced imaging have been applied to patients with unprovoked VTE (Monreal et al., 2004). However, for the time being, these offer questionable predictive value (Nordstrom et al., 1994) and may not be cost-effective.

In spite of such failures, there is an urgent need to identify reliable markers of cancers, presumably based on the identification of early hemostatic markers of activation of the coagulation cascade conferring a specific pattern for malignancy. The findings in this field may pave the way for the development of commercially available diagnostic kits capable to identify cancers at an early phase.

Interactions between hemostasis factors and cancer cells: The interactions between components of the hemostatic system and cancer cells are multifaceted and complex. The physiological mechanisms of thrombus promotion in malignancy include some general responses of the host to the tumor (acute phase, inflammation, angiogenesis) and specific interactions of tumor cells expressing Tissue Factor (TF), with the clotting/fibrinolysis systems and with blood (leukocytes, platelets) or vascular cells. It is still difficult to rank the relative weight of these multiple interactions only on the basis of the well-recognized clinical evidence of enhanced thrombotic episodes in tumor patients (Donati and Falanga, 2001).

There is currently renewed increasing scientific evidence that the coagulation system and the activation of platelets play an instrumental role in the progression and regulation of malignant growth and facilitation of metastasis. Important molecular crosstalk occurs between platelets, leukocytes, endothelial cells and tumor cells controls. Understanding such interactions clearly opens the potential for the development of novel cancer treatments based on the inhibition of cancer promoters (Labelle et al., 2001). As such, the underlying mechanism by which coagulation factors promote tumor cell growth, invasion, metastasis and angiogenesis has recently become a hot topic in the field of cancer research (Ma et al., 2011).

The confirmation that small daily doses of aspirin reduce metastasis and help treatment of some cancers is a most recent indicator of the role that platelets and coagulation factors can play in cancer (Rothwell et al., 2012). It is increasingly believed that blocking the chain of events of the coagulation cascade upstream of its activation process have a strong potential for limiting the progression of tumors (Zacharski, 2011) and may translate into improved therapy and patient survival. Although, the beneficial effects of low molecular weight heparins (LMWH) in cancer-related VTE prevention and treatment is well established, their effect on survival in cancer patients, remains controversial (Meyer et al., 2011; Doormaal et al., 2011), suggesting that every anticoagulation approach to restrain activation of coagulation and platelets should be looked for.

\section{III-Platelet role in cancer:}

III-a Platelet count: By their capacity, upon activation, to adhere to exposed sub-endothelium in a flowdependent manner, to aggregate and to facilitate thrombin generation, platelets have long been recognized as the primary hemostatic tool, with deficiencies resulting in bleeding and up-regulation favoring thrombosis. Yet, increasing evidence indicates that platelets fulfill a much wider role in balancing health and disease. Platelets are a source of active metabolites and proteins, promote heterotypic cell interactions and provide a biologically active surface, together with a capacity to release cell-derived micro particles that promote coagulation and protease activation. Platelets also exert an active role in sepsis, inflammation, tissue regeneration and control of 
infection (including promoting the innate immune response) (Nurden, 2011).

Furthermore, observations have suggested that platelets not only augment the growth of primary tumors via angiogenesis but endow tumor cells physical and mechanical support to evade the immune system and, through induction of Epithelial-Mesenchymal-Like Transition (EMT) of tumor cells, facilitating extravasation to secondary organs, the basis of metastatic disease. Many laboratory and animal studies have identified specific targets for antiplatelet therapy that may be advantageous as adjuncts to existing cancer treatments (Jain et al., 2010).

The involvement of platelets and coagulation factors in hematogenous tumor metastasis has long been recognized. As a more direct evidence of platelet involvement in the development of malignant tumors, a relationship between elevated platelet count and malignant tumors was reported as early as 1872 by (Tranum and Haut, 1974). Ayhan et al. (2006), demonstrated that higher preoperative platelet counts, even if lying within the normal range (150.000-400.000 microl $^{-1}$ ), may reflect poor prognostic factors such as cervical involvement and high grade among patients with endometrial carcinoma. These authors went even further, questioning the necessity of radical hysterectomy in patients with higher counts (Ayhan et al., 2006). Similar observations were made in other gynecological malignancies (Hernandez et al., 1992; Zeimet et al., 1994) and in gastrointestinal tumors (Ikeda et al., 2002; Shimada et al., 2004).

III-b Platelet activation markers: Platelets can be activated by human and experimental tumor cells, a process described in 1968 as "Tumor Cell-Induced Platelet Aggregation» (TCIPA). It became apparent that this aggregation correlates with the metastatic potential of cancer cells in vivo (Karpatkin et al., 1988; Joseph, 1995; Al-Mondhiry, 1983). Compared with those in complete remission, patients with active malignant disease have elevated levels of beta-thromboglobulin and platelet factor 4 (Al-Mondhiry, 1983) Circulating activated platelets have also been evidenced in cancer patients by detection of the platelet membrane antigens CD62 (p-selecting) and CD63 (Wehmeier et al., 1991). Tumor cells or membrane vesicles that have been shed spontaneously from tumor cells can directly aggregate platelets in vitro (Jamieson and Scipio, 1982) and can induce platelet aggregation through the release of proaggregatory mediators including adenosine diphosphate, thrombin and a cathepsin-like cysteine proteinase (Grignani and Jamieson, 1988).

Metastasis comprises multiple, consecutive steps. Several cell adhesion molecules are involved in the various stages of cancer metastasis (Huang et al., 1997). CD 62P-derived from platelets can bind to a variety of human cancers and human cancer-derived cell lines, such as colon cancer, lung cancer including small-cell lung cancer, breast cancer, malignant melanoma, gastric cancer, neuroblastoma and adenoid cystic carcinoma of the salivary gland. An increasing body of in vivo experimental evidence indicates that $\mathrm{P}$ selection plays important roles in the growth and metastasis of cancers (Chen and Geng, 2006). The ligand molecules on cancer cells for P-selection, however, remain unidentified. Several lines of evidence suggest that the binding of human cancer cells, derived from various organs and/or tissues, to P-selection may be mediated by very different glycoprotein ligands (Palumbo et al., 2005). Platelet depletion, or even an inhibition of TCIPA, reliably diminishes metastasis, seemingly without affecting the growth of established tumors, in different in vivo models of experimental pulmonary metastasis as well as in a murine model of spontaneous metastasis (Palumbo et al., 2005). Platelet/tumor cell/endothelial interactions have also been reported helping in establishing metastatic lesions (Rickles and Falanga, 2001).

III-c Platelet growth factors on immune cell function, tumor progression and tethering: Platelets and their byproducts, released upon platelet activation through degranulation, appear to limit the ability of Natural Killer (NK) cells to lyse tumor cells in vitro and in vivo (Palumbo et al., 2005). Furthermore, plateletderived transforming growth factor- $\beta$ (TGF- $\beta$ ) downregulates the activating immunoreceptor NKG2D on NK cells (Kopp et al., 2009) and has been shown to favor EMT in various cancer cell lines, thereby potentially facilitating metastasis.

A number of growth factors supporting tumor growth and possibly angiogenesis, such as PlateletDerived Growth Factor (PDGF), Vascular Endothelial Growth Factor (VEGF) and angiopoetin-1, are released by platelets, further interplaying and enhancing tumor progression (Kepner and Lipton, 1981; Mohle et al., 1997; Nierodzik and Karpatkin, 2006) and regulating tumor vascular biology, preventing intralesional hemorrhages (Noe et al., 2008; 2009). Furthermore, some platelet byproducts/tumor cell receptor interactions are associated with more tumor biological aggressiveness. PDGFR-alpha, a receptor for PDGF, expressed in invasive breast carcinomas is a good example of this phenomenon (Oft et al., 1998).

Dendritic Cells (DCs) are key players in the initiation of adaptive immune responses and are currently exploited in immunotherapy for treatment of cancer (Cruz et al., 2012). Platelets seem to secrete a soluble DC-activating factor and are active elements of the immune system that might play a role in balancing 
the ability of DCs to polarize $\mathrm{T}$ cell responses (Cognasse et al., 2008).

Glycoprotein Ib-IX-V-complex (GPIb-IX-V) along with GPVI on the surface of platelets are primarily responsible for initial platelet adhesion and activation by binding to their major legend, Von Willebrand Factor (VWF) and collagen, respectively (Smyth et al., 2009). Glycoprotein GPIb $\alpha$ and the A1 domain of VWF immobilized on collagen or on the surface of activated platelets are crucial for the initial tethering and rolling of platelets at the site of vascular injury. Engagement of GPIb $\alpha$ is required for downstream activation of the integrin receptor and is thus an important initial step in the cascade that can finally lead to firm thrombus formation (Erpenbeck and Schon, 2010). Exceptionally, some tumor cell lines, such as MCF7 cells, derived from a human breast cancer, may express GPIb $\alpha$ themselves (Oleksowicz et al., 1995). Inhibition of GPIb $\alpha$ could enhance metastasis, an observation in apparent contrast to most publications dealing with platelets and metastasis. It is conceivable that blockade of platelet GPIb $\alpha$ could result in an increased availability of P-selectin for tumor cell-endothelial interactions, thus supporting the attachment of tumor cells to the vascular (Erpenbeck and Schon, 2010).

III-d Platelet integrins: Heterodimeric receptors of the $\beta 1$ and $\beta 3$ integrin families mediate platelet adhesion and aggregation in hemostasis and thrombosis. In resting platelets, integrins are expressed in a lowaffinity state but they shift to a high-affinity state and efficiently bind to their ligands in response to cellular activation. The 2 interns considered to be most important for platelet adhesion and aggregation are integrins $\alpha_{2} \beta_{1}$ and $\alpha_{\mathrm{II}} \mathrm{b} \beta_{3}$ (GPIIb/IIIa) (Nieswandt et al., 2009). Although little is known about $\alpha_{2} \beta_{1}$ in plateletdependent cancer cell metastasis, this integrin receptor appear to play a role for the adhesion of certain cancer cell lines, like pancreatic tumors, to the extracellular matrix (Hall et al., 2008). In contrast, the relation between $\alpha_{\mathrm{II}} \mathrm{b} \beta_{3}$ (GPIIb/IIIa) and metastasis of different tumor cell lines has long been established rendering this receptor an attractive target for anti-metastatic therapy (Erpenbeck and Schon, 2010). Activation of platelet GPIIb/IIIa seems to be necessary for the release of angiogenic factors stored in platelet granules, such as VEGF, crucial for tumor spreading, PDGF, TGF- $\beta$ and fibrinogen (Trikha et al., 1998; Amirkhosravi et al., 1999). Many tumor cell lines express themselves the same integrins that are normally found on platelets, namely GPIb and $\alpha \mathrm{IIb} \beta 3$ (GPIIb/IIIa), adding to their malignant potential (Trikha et al., 1998; Chen et al., 1997). Therefore, it is not surprising to consider an independent role for their ligand $\mathrm{vWF}$ in tumor metastasis (Terraube et al., 2007).
III-e Adenosine diphosphate: Adenosine Diphosphate (ADP) is a platelet agonist that causes platelet shape change and aggregation as well as generation of thromboxane $\mathrm{A}_{2}$, another platelet agonist, through its effects on a family of purinergic receptors: P2Y1, P2Y12 and P2X1 (Jianguo et al., 2002). Several tumor cell lines possess the ability to generate ADP themselves inducing a TCIPA (Boukerche et al., 1994).

IV Activation of Coagulation and cancer: The prothrombotic state of cancer is driven by specific oncogenic events. Activation of the coagulation cascade appears integrally linked to the processes of tumor growth, metastasis and angiogenesis (Tarek and Khorana, 2009).

IV-a Tissue factor: Tissue Factor (TF) is best known as the primary cellular initiator of blood coagulation. After vessel injury, the TF: FVIIa complex activates the coagulation protease cascade, which leads to fibrin deposition and activation of platelets (Mackman, 2004).

In cancer-related thrombosis, the role of $\mathrm{TF}$ has gathered the most attention (Tarek and Khorana, 2009). This trans-membrane glycoprotein is expressed in a variety of human cancers, induced by activation of oncogenes or inactivation of tumor suppressor genes (Yu et al., 2005). Over-expression of TF in tumor cells or elevated TF levels in association with micro-particles in the systemic circulation may contribute to systemic hypercoagulability (Dvorak et al., 1981; Khorana et al., 2007; 2008; Tesselaar et al., 2007; Uno et al., 2007). In experimental models, cell lines often release TFpositive Microparticles (MP) triggering thrombosis (Wang et al., 2012). Translational research in humans, conducted by Doormaal et al. (2012) on 43 cancer patients without VTE at study entry and 22 healthy volunteers, followed the markers of in vivo and MPdependent coagulation prospectively for six months and for the development of VTE. They concluded that although, median TF-mediated Xa-generation and median VIIa-dependent fibrin generation test were higher in the VTE group compared with the non-VTE group. In this exploratory study the overall hypercoagulable state in cancer patients was not associated directly with the MP phospholipiddependent procoagulant activity. However, in the patients who developed VTE within six months when compared to those who did not, an increased MP procoagulant activity was present already at baseline, suggesting it could be used to predict VTE (Doormaal et al., 2012).

Furthermore, TF may exert non-hemostatic roles in the generation of coagulation proteases and subsequent 
activation of Protease Activated Receptors (PARs) on vascular cells. This TF-dependent signaling contributes to a variety of biological processes, including inflammation, angiogenesis, metastasis and cell migration (Tarek and Khorana, 2009). Interestingly, inhibition of PAR1 or the presence of specific polymorphism such as 506I/D are associated with a better outcome in patients with breast cancer (Eroglu et al., 2012).

Finally, TF pathway regulates mechanisms which involve plasmin and matrix metallo-proteinases, both of which seem to be critical in oral carcinogenesis (Yapijakis et al., 2012).

IV-b Factor Xa and TF-FVIIa-FXa complex: Coagulation factor zymogens activated upstream of thrombin, including Factor $\mathrm{Xa}(\mathrm{FXa})$, may also exert signalling via PARs and thus induce cellular effects independent of thrombin generation (Krupiczojc et al., 2008). The combination of FVIIa and FXa, but not FVIIa alone, strongly induced migration of tumor cells by a pathway that probably involves PAR2, but not PAR1, activation. TF-FVIIa-mediated signaling in human breast cancer cells occurs most efficiently by formation of the TF-FVIIa-FXa complex (Jiang et al., 2004). One of the physiological consequences of this signaling pathway is enhanced cancer cell migration mediated by mTOR pathway activation (Jiang et al., 2008). Furthermore, the TF-FVIIa-FXa complex prevents apoptosis in breast cancer cells by a thrombinindependent pathway (Jiang et al., 2006). Quite unexpectedly, FXa alone markedly diminished the migration of different cancer cell lines of various origins (breast, lung and colon cancer cells) and FXa mediated inhibition of cancer cell migration was specific, as it was inhibited by TAP (a specific FXa inhibitor) but not by Hirudin (a specific thrombin inhibitor) (Borensztajn et al., 2009). The role of specific $\mathrm{Xa}$ inhibitors in the prevention of cancer related thrombosis, remains however controversial although initial results support further study of apixaban, a specific oral FXa inhibitor, in phase III trials to prevent VTE in cancer patients receiving chemotherapy (Levine et al., 2012).

IV-c Thrombin: Thrombin, the key terminal enzyme of coagulation, also promotes angiogenesis and stimulates tumor-platelet adhesion, adhesion to endothelium, tumor implantation, tumor cell growth and metastasis. The thrombin receptor is expressed on many tumor cell lines and on breast tumor biopsy specimens (Ruf et al., 2010). In addition to the mitogenic effects on fibroblast, smooth muscle cells and endothelial cells, thrombin also exerts direct effects on cancer cells (Green and Karpatkin, 2010). It is also worth noting that thrombin is the key legend of
PAR firing inflammation and cell migration (Eroglu $e t$ al., 2012). Furthermore, thrombin-induced Cathepsin $\mathrm{D}$, in term, contributes to the malignant phenotype by inducing tumor cell migration, nodule growth, metastasis and angiogenesis ( $\mathrm{Hu}$ et al., 2008). The activation of fibrinogen by thrombin and its cleavage to fibrin monomers result in the rapid formation of fibrin matrix. Furthermore, it is well documented that fibrinogen and cross-linked fibrin reside inside the tumor stroma (Yapijakis et al., 2012). Paradoxically, thrombin-mediated thrombomodulin may act through attenuation of the tumor-promoting properties of thrombin, but it also may function as a cell-to-cell adhesion molecule, independently of its anticoagulant action (Yapijakis et al., 2012). Not surprisingly, in xenographic tumour models, direct thrombin inhibitors-like hirudin-have shown a significant carcinostatic effect (Nowak et al., 2007). By virtue of their anti-thrombin properties and beyond, heparin or LMWH remain the cornerstone agents for the treatment and prevention of cancer-related thrombosis (Kahn et al., 2012).

Many studies alluded to the beneficial effects of LMWH on survival in cancer patients and a systematic review concluded that LMWH improves overall survival in cancer patients, even in those with advanced disease (Lazo-Langner et al., 2007). A recent study, however, did not show a survival benefit of nadroparin in patients with advanced prostate, lung, or pancreatic cancer (Doormaal et al., 2011).

IV-d Fibrinogen and Fibrin: Fibrinogen is the final and most important component of the coagulation cascade, as well as a major determinant of blood viscosity and blood flow and an important acute phase reactant. Epidemiological studies increasingly suggests that elevated plasma fibrinogen levels are associated with an increased risk of cardiovascular disorders, including Ischaemic Heart Disease (IHD), stroke and other thromboembolisms (Meade et al., 1986; Wilhelmsen et al., 1984). Hyperfibrinogenemia may be a predictor for poor chemo-response and has a potential role as independent prognostic factors in ovarian, rectal and renal cell carcinoma patients. Moreover, it can be used as a biomarker to predict therapeutic response (Qiu et al., 2012; Xiao et al., 2011; Lu et al., 2011) or a risk predictor for smoking-related cancers (Silva et al., 2010).

There is also evidence that fibrin deposition induced by tumour cell-associated tissue factor and probably platelets, protect tumor cells from a recognition by NK cells contributing to enhancing metastasis.

IV-e Natural anticoagulants: Activated Protein C (APC) and Protein $\mathrm{C}$ Inhibitor (PCI) are the major components of the anticoagulant protein $\mathrm{C}$ pathway and are the two proteins raising most interest for their 
potential role in regulating cancer. APC and PCI play many roles not only in the regulation of hemostasis but also in cell inflammation, proliferation, apoptosis, tumor cell migration, invasion and metastasis. APC promotes tumor cell invasion by EPCR-mediated and PAR-1-mediated protease activity whereas PCI inhibits tumor cell invasion in vitro by its protease inhibitory activity and suppresses tumor cell growth, metastasis and angiogenesis independent of its protease inhibitor activity (Suzuki and Hayashi, 2007).

Abnormalities in Protein $\mathrm{S}$ seem to be rather functional with reported dysregulation of Snitrosylation, a process that related to cancer progression and dissemination (Wang, 2012). Quantitation of protein S, seems however, non-specific and redundant (Battistelli et al., 2005).

The role of Antithrombin (AT) is controversial as early studies have reported an elevated level of AT in patients with bladder and renal malignancy (Zietek et al., 1997a; 1997b). Others have reported that their cancer patients with localized prostate cancer had significantly lower levels of AT III activity and higher plasma D-dimer levels (Fidan et al., 2012). Furthermore, others have advocated the use of low AT and raised D-Dimer as prognostic markers for gynecological malignancy (Koh et al., 2001; 2006). As one would have expected, elevated Thrombin Antithrombin Complex (TAT) observed in malignancy correlated with its severity and was often associated with abnormalities in the Thrombin Activatable Fibrinolysis Inhibitor (TAFI) (Hong et al., 2010; Kaftan et al., 2011). Further studies are deemed necessary to clarify the possible relation between AT level and cancer.

Tissue factor pathway inhibitor, the physiological inhibitor of TF, may also play a role in cancer. A proapoptotic effect of TFPI has been found in breast cancer cells in vitro, while corresponding downregulation of endogenous TFPI resulted in reduced apoptotic activity. Newer data suggest an anti-metastatic effect of TFPI and suggest it can be a novel therapeutic approach in cancer.

IV-f Fibrinolysis: Early studies have demonstrated without doubt, the role of activated coagulation and impaired fibrinolysis in patients with cancer (Laug et al., 1975; Rocha et al., 1989; Zacharski et al., 1992). There is now, however, good evidence that parts of the fibrinolytic system, such as urokinase-type plasminogen activator and its receptor ("uPAR"), can be used as strong predictors of outcome and targets in several types of cancer, specifically breast cancer (Korte, 2000; Al-Hassan et al., 2012). Disseminated intravascular coagulation with excessive fibrinolysis has been described in the context of advanced prostatic carcinomas (Hyman et al., 2011). Adjuvant chemotherapy in cases of breast or prostatic carcinomas further interferes with the fibrinolytic system favoring thrombosis (Oberhoff et al., 2000; Varenhorst and Risberg, 1981).

\section{CONCLUSION}

Applications for translational therapy of cancer: Challenging issues and unresolved questions still need to be addressed to understand the complexity existing between coagulation factors and platelet components and the different stages of cancer progression. However, important findings have been obtained in the last few years in the understanding of cancer-associated thrombosis that can serve to understand the link between coagulation and cancer. Such knowledge is opening perspectives not only to better identify and treat patients at risk of VTE, but also possible to design new, possibly individualized therapy, to stop cancer progression and metastasis. Much bench work and clinical developments are still needed in the comprehension of the intimate relationships existing between activation of the coagulation system and platelets and cancer progression and metastasis. The role that coagulation and platelets play at the distinct stages involved in cancer progression, in particular in tumour cell protection and hematogenous metastasis, needs major clarifications. Recent discoveries are leading clinicians to consider new therapeutic applications of anticoagulant therapies or new drugs targeting specific platelet functions in cancer patients' management. Possibility to use anticoagulants, either already available or to be developed (LMWH, aspirin, warfarin, cyclooxygenase inhibitors, P-selectin inhibitor, integrin $\alpha \operatorname{IIb} \beta 3$ antagonists and others) in the treatment of tumour progression and inhibition of metastasis represent a promessing avenue of clinical research development, already found effective in animal models (Gay and Felding-Habermann, 2011).

Coagulation (TF, FXa, FVIIa, AT, fibrinogen, thrombin, $\mathrm{PC}, \mathrm{PCa}, \mathrm{TFPI})$ and platelet (P-selectin, PDGF, TGF- $\beta$, VEGF, PF4) markers are clearly associated, as causative agents or as markers, to cancer development and evolution. Following their evolving levels in patients can therefore also be considered as a means to optimize treatment options and possibly they can also serve as early biomarkers for dormant tumors.

\section{REFERENCES}

Al-Hassan, N.N., A. Behzadian, R. Caldwell, V.S. Ivanova and V. Syed, et al., 2012. Differential roles of UPAR in peritoneal ovarian carcinomatosis. Neoplasia, 14: 259-270. 
Al-Mondhiry, H., 1983. Beta-Thromboglobulin and platelet-factor 4 in patients with cancer: correlation with the stage of disease and the effect of chemotherapy. Am. J. Hematol., 14: 105-111. PMID: 6188373

Amirkhosravi, A., M. Amaya, F. Siddiqui, J.P. Biggerstaff and T.V. Meyer et al., 1999. Blockade of GpIIb/IIIa inhibits the release of Vascular Endothelial Growth Factor (VEGF) from tumor cell-activated platelets and experimental metastasis. Platelets, 10: 285-292. PMID: 16801104

Ayhan, A., G. Bozdag, C. Taskiran, M. Gultekin and K. Yuce et al., 2006. The value of preoperative platelet count in the prediction of cervical involvement and poor prognostic variables in patients with endometrial carcinoma. Gynecol. Oncol., 103: 902-905. PMID: 16828847

Baron, J.A., G. Gridley, E. Weiderpass, O. Nyren and M. Linet, 1998. Venous thromboembolism and cancer. Lancet, 351: 1077-1080. DOI: 10.1016/S0140-6736(97)10018-6

Battistelli, S., A. Vittoria, R. Cappelli, M. Stefanoni and F. Roviello, 2005. Protein $\mathrm{S}$ in cancer patients with non-metastatic solid tumours. Eur. J. Surg. Oncol., 31: 798-802. PMID: 15993032

Blom, J.W., C.J. Doggen, S. Osanto and F.R. Rosendaal 2005. Malignancies, prothrombotic mutations and the risk of venous thrombosis. JAMA., 293: 715722. DOI: $10.1001 /$ jama.293.6.715

Borensztajn, K., M.F. Bijlsma, P.H. Reitsma, M.P. Peppelenbosch and C.A. Spek, 2009. Coagulation factor Xa inhibits cancer cell migration via protease-activated receptor-1 activation. Thromb. Res., 124: 219-25. PMID: 9250659

Boukerche, H., M Benchaibi, O. Berthier-Vergnes, G. Lizard and M. Bailly et al., 1994. Two human melanoma cell-line variants with enhanced in vivo tumor growth and metastatic capacity do not express the beta 3 integrin subunit. Eur. J. Biochem., 220: 485-491. PMID: 8125107

Chen, M. and J.G. Geng, 2006. P-selectin mediates adhesion of leukocytes, platelets and cancer cells in inflammation, thrombosis and cancer growth and metastasis. Arch Immunol. Exp. Warsz, 54: 75-84. PMID: 16648968

Chen, YQ., M. Trikha, X. Gao, R. Bazaz and A.T. Porter et al., 1997. Ectopic expression of platelet integrin alphaIIb beta3 in tumor cells from various species and histological origin. Int. J. Cancer, 72: 642-648. PMID: 9259405

Cognasse, H.H., F. Cognasse, S. Palle, P. Chavarin and T. Olivier et al., 2008. Direct contact of platelets and their released products exert different effects on human dendritic cell maturation. BMC, Immunol., 9: 54: 54-54. PMID: 18817542
Cruz, L.J., P.J. Tacken, F. Rueda, J.C. Domingo and F. Albericio et al., 2012. Targeting nanoparticles to dendritic cells for immunotherapy. Methods Enzymol., 509: 143-163. PMID: 22568905

Donati, M.B. and A. Falanga, 2001. Pathogenetic Mechanisms of Thrombosis in Malignancy. Acta Haematol., 106: 18-24. DOI: 10.1159/000046585

Doormaal, F., A. Kleinjan, R.J. Berckmans, N. Mackman and D. Manly et al., 2012. Coagulation activation and microparticle-associated coagulant activity in cancer patients. An exploratory prospective study. Thromb Haemost, 108: 160-165. PMID: 22535219

Doormaal, F.F., D.M. Nisio, H.M. Otten, D.J. Richel and M. Prins et al., 2011. Randomized trial of the effect of the low molecular weight heparin nadroparin on survival in patients with cancer. J. Clin. Oncol., 29: 2071-2076.

Dvorak, H.F., S.C. Quay, N.S. Orenstein, A.M. Dvorak and P. Hahn et al., 1981. Tumor shedding and coagulation. Science, 212: 923-924. PMID: 7195067

Eroglu, A., A. Karabiyık and N. Akar, 2012. The association of protease activated receptor 1 gene 506 I/D polymorphism with disease-free survival in breast cancer patients. Ann. Surg. Oncol., 19: 1365-1369. PMID: 21822552

Erpenbeck, L. and M.P. Schon, 2010. Deadly allies: The fatal interplay between platelets and metastasizing cancer cells. Blood, 115: 3427-3436. DOI: 10.1182/blood-2009-10-247296

Estrov, Z., M. Talpaz, G. Mavligit, R. Pazdur and D. Harris et al., 1995. Elevated plasma thrombopoietic activity in patients with metastatic cancer-related thrombocytosis. Am. J. Med., 98: 551-558. PMID: 7539977

Fidan, E., H. Kavgaci, A. Orem, M. Yilmaz and B. Yildiz et al., 2012. Thrombin activatable fibrinolysis inhibitor and thrombin-antithrombinIII-complex levels in patients with gastric cancer. Tumour Biol., PMID: 22535370

Gay, L.J. and B. Felding-Habermann, 2011. Contribution of platelets to tumour metastasis. Nat. Rev. Cancer, 11: 123-134. PMID: 21258396

Green, D. and S. Karpatkin, 2010. Role of thrombin as a tumor growth factor. Cell. Cycl., 9: 656-661. PMID: 20190559

Greenwell, J., 1991. Doctor georges phillipe trousseau, royal physician. Hawaiian J. History Hawaii Historical Soc., 25: 121-145.

Grignani, G. and G.A. Jamieson, 1988. Platelets in tumor metastasis: Generation of adenosine diphosphate by tumor cells is specific but unrelated to metastatic potential. Blood, 71: 844-849. PMID: 2833329 
Hall, C.L., C.W. Dubyk, T.A. Riesenberger, D. Shein and E.T. Keller et al., 2008. Type I collagen receptor (alpha2beta1) signaling promotes prostate cancer invasion through RhoC GTPase. Neoplasia, 10: 797-803. PMID: 18670640

Hernandez, E., M. Lavine, C.J. Dunton, E. Gracely and J. Parker, 1992. Poor prognosis associated with thrombocytosis in patients with cervical cancer. Cancer, 15: 2975-2977. DOI: 10.1002/10970142(19920615)69:12<2975::AID-

CNCR2820691218>3.0.CO;2-A

Hong, S.K., D.W. Ko, J. Park, I.S. Kim and S.H. Doo et al., 2010. Alteration of antithrombin III and Ddimer levels in clinically localized prostate cancer. Korean J. Urol., 51: 25-29. DOI: 10.4111/kju.2010.51.1.25

Hu, L., J.M. Roth, P. Brooks, J. Luty and S. Karpatkin, 2008. Thrombin up-regulates cathepsin D which enhances angiogenesis, growth and metastasis. Cancer Res., 68: 4666-4673. PMID: 18559512

Huang, Y.W., R. Baluna and E.S. Vitetta, 1997. Adhesion molecules as targets for cancer therapy. Histol. Histopathol., 12: 467-477. PMID: 9151136

Hyman, D.M., G.A. Soff and L.J. Kampel, 2011. Disseminated intravascular coagulation with excessive fibrinolysis in prostate cancer: A case series and review of the literature. Oncology, 81: 119-125. PMID: 21986538

Ikeda, M., H. Furukawa, H. Imamura, J. Shimizu and H. Ishida et al., 2002. Poor prognosis associated with thrombocytosis in patients with gastric cancer. Ann. Surg. Oncol., 9: 287-291. PMID: 11923136

Jain, S., J. Harris and J. Ware, 2010. Platelets: linking hemostasis and cancer. Arterioscl. Thromb. Vasc. Biol., 30: 2362-2367. PMID: 21071699

Jamieson, G.A. and A.R. Scipio, 1982. Interaction of Platelets and Tumor Cells. 1st Edn., A.R. Liss, New York, ISBN-10: 0845100890, pp: 523.

Jiang, X., M.A. Bailly, T.S. Panetti, M. Cappello and W.H. Konigsberg et al., 2004. Formation of tissue factor-factor VIIa-factor Xa complex promotes cellular signaling and migration of human breast cancer cells. J. Thromb. Haemost, 2: 93-101. PMID: 14717972

Jiang, X., S. Zhu, T.S. Panetti and M.E. Bromberg, 2008. Formation of tissue factor-factor VIIa-factor $\mathrm{Xa}$ complex induces activation of the mTOR pathway which regulates migration of human breast cancer cells. Thromb. Haemost, 100: 127133. PMID: 18612547

Jiang, X., Y.L. Guo and M.E. Bromberg, 2006. Formation of tissue factor-factor VIIa-factor Xa complex prevents apoptosis in human breast cancer cells. Thromb. Haemost., 96: 196-201. PMID: 16894464
Jianguo, J., T.M. Quinton, J. Zhang, S.E. Rittenhouse and S.P. Kunapuli, 2002. Adenosine Diphosphate (ADP)-induced thromboxane A2generation in human platelets requires coordinated signaling through integrin $\alpha \mathrm{IIb} \beta 3$ and ADP receptors. Blood, 99: 193-198. DOI: 10.1182/blood.V99.1.193

Joseph, M., 1995. Immunopharmacology of Platelets. 1st Edn., Academic Press, London, ISBN-10: 0080534562, pp: 250.

Kaftan, O., B. Kasapoglu, M. Koroglu, A. Kosar and S.K. Yalcin, 2011. Thrombin-activatable fibrinolysis inhibitor in breast cancer patients. Med. Princ Pract, 20: 332-335. PMID: 21576992

Kahn, S.R., W. Lim, A.S. Dunn, M. Cushman and F. Dentali et al., 2012. Prevention of VTE in nonsurgical patients: Antithrombotic Therapy and Prevention of Thrombosis, 9th ed: American College of Chest Physicians Evidence-Based Clinical Practice Guidelines. Chest, 141: e195S226S. PMID: 22315261

Karpatkin, S., E. Pearlstein, C. Ambrogio and B.S. Coller, 1988. Role of adhesive proteins in platelet tumor interaction in vitro and metastasis formation in vivo. J. Clin. Invest., 81: 1012-1019. DOI: 10.1172/JCI113411

Kepner, N. and A. Lipton, 1981. A mitogenic factor for transformed fibroblasts from human platelets. Cancer Res., 41: 430-432. PMID: 6256066

Khorana, A.A., C.W. Francis, K.E. Menzies, J.G. Wang and O. Hyrien et al., 2008. Plasma tissue factor may be predictive of venous thromboembolism in pancreatic cancer. J. Thromb. Haemost., 6: 19831985. DOI: 10.1111/j.1538-7836.2008.03156.x

Khorana, A.A., S.A. Ahrendt, C.K. Ryan, C.W. Francis and R.H. Hruban et al., 2007. Tissue factor expression, angiogenesis and thrombosis in pancreatic cancer. Clin. Cancer Res., 13: 28702875. PMID: 17504985

Koh, S.C, K.F. Tham, K. Razvi, P.L. Oei and F.K. Lim et al., 2001. Hemostatic and fibrinolytic status in patients with ovarian cancer and benign ovarian cysts: could D-dimer and antithrombin III levels be included as prognostic markers for survival outcome? Clin. Applied Thromb. Hemost, 7: 141148. PMID: 11292192

Koh, S.C., R. Khalil, F.K. Lim, A. Ilancheran and M. Choolani, 2006. The association between fibrinogen, von Willebrand Factor, antithrombin III and D-dimer levels and survival outcome by 36 months from ovarian cancer. Clin. Applied Thromb. Hemost, 12: 3-8. PMID: 16444428

Kopp, H.G., T. Placke and H.R. Salih, 2009. Plateletderived transforming growth factor-beta down regulates NKG2D thereby inhibiting natural killer cell antitumor reactivity. Cancer Res., 69: 77757783. PMID: 19738039 
Korte, W., 2000. Changes of the coagulation and fibrinolysis system in malignancy: their possible impact on future diagnostic and therapeutic procedures. Clin. Chem. Lab. Med., 38: 679-692. PMID: 11071061

Krupiczojc, M.A., C.J. Scotton and R.C. Chambers, 2008. Coagulation signalling following tissue injury: Focus on the role of factor Xa. Int. J. Biochem. Cell Biol., 40: 1228-1237. PMID: 18420447

Labelle, M., S. Begum and R.O. Hynes, 2001. Direct signaling between platelets and cancer cells induces an epithelial-mesenchymal-like transition and promotes metastasis. Cancer Cell, 20: 576-590. DOI: $10.1016 /$ jecr.2011.09.009

Laug, W.E., P.A. Jones and W.F. Benedict, 1975. Relationship between fibrinolysis of cultured cells and malignancy. J. Natl. Cancer Inst., 54: 173-179. PMID: 123008

Lazo-Langner, A., G.D. Goss, J.N. Spaans, M.A. Rodger, 2007. The effect of low-molecular-weight heparin on cancer survival. A systematic review and meta-analysis of randomized trials. J. Thromb Haemost, 5: 729-37. PMID: 17408406

Levine, M.N., C. Gu, H.A. Liebman, C.P. Escalante and S. Solymoss et al., 2012. A randomized phase II trial of apixaban for the prevention of thromboembolism in patients with metastatic cancer. J. Thromb. Haemost, 10: 807-814. PMID: 22409262

Lu, K., Y. Zhu, L. Sheng, L. Liu and L. Shen et al., 2011. Serum fibrinogen level predicts the therapeutic response and prognosis in patients with locally advanced rectal cancer. Hepatogastroenterology, 58: 1507-10. PMID: 21940318

Ma, Y.Y., X.J. He, H.J. Wang, Y.J. Xia and S.L. Wang et al., 2011. Interaction of coagulation factors and tumor-associated macrophages mediates migration and invasion of gastric cancer. Cancer Sci., 102: 336-342. DOI: 10.1111/j.1349-7006.2010.01795.x

Mackman, N., 2004. Role of tissue factor in hemostasis, thrombosis and vascular development. Arterioscler Thromb. Vasc. Biol., 24: 1015-1022. DOI: 10.1161/01.ATV.0000130465.23430.74

Meade, T.W., S. Mellows, M. Brozovic, G.J. Miller and R.R. Chakrabarti et al., 1986. Haemostatic function and ischaemic heart disease: Principal results of the Northwick park heart study. Lancet, 2: 533-557. PMID: 2875280

Meyer, G., B. Besse, S. Friard, P. Girard and P. Corbi et al., 2011. Effect of tinzaparin on survival in nonsmall-cell lung cancer after surgery. TILT: tinzaparin in lung tumours. Rev. Mal. Respir., 28: 654-659. PMID: 21645836
Mohle, R., D. Green, M.A. Moore, R.L. Nachman and S. Rafii, 1997. Constitutive production and thrombin-induced release of vascular endothelial growth factor by human megakaryocytes andplatelets. Proc. Natl. Acad. Sci., 94: 663-668. PMID: 9012841

Monreal, M., A.W. Lensing, M.H. Prins, M. Bonet and J. Fernández-Llamazares et al., 2004. Screening for occult cancer in patients with acute deep vein thrombosis and pulmonary embolism. J. Thromb. Haemost, 2: 876-881. PMID: 15140120

Nierodzik, M.L. and S. Karpatkin, 2006. Thrombin induces tumor growth, metastasis and angiogenesis: Evidence for a thrombin-regulated dormant tumor phenotype. Cancer Cell, 10: 355362. PMID: 17097558

Nieswandt, B., D. Varga-Szabo and M. Elvers, 2009. Integrins in platelet activation. J. Thromb. Haemost, 7: 206-209. PMID: 19630801

Noe, H.T.B., T. Goerge and D.D. Wagner, 2009. Platelets: Guardians of tumor vasculature. Cancer Res., 69: 5623-5623. DOI: 10.1158/00085472.CAN-09-1370

Noe, H.T.B., T. Goerge, S.M. Cifuni, D. Duerschmied and D.D. Wagner, 2008. Platelet granule secretion continuously prevents intratumor hemorrhage. Cancer Res., 68: 6851-6858. DOI: 10.1158/00085472.CAN-08-0718

Nordstrom, M., B. Lindbkad, H. Anderson, D. Bergqvist and T. Kjellstrom et al., 1994. Deep venous thrombosis and occult malignancy: An epidemiological study. BMJ., 308: 891-894.

Nowak, G., M. Lopez and M. Zieger, 2007. Thrombin induced tumour growth-pharmacological control. Hamostaseologie, 27: 105-110. PMID: 17479173

Nurden, A.T., 2011. Platelets, inflammation and tissue regeneration. Thromb. Haemost, 105: 13-33. PMID: 21479340

Oberhoff, C., U.H. Winkler, O. Hoffmann and A.E. Schindler, 2000. Adjuvant CMF-chemotherapy and haemostasis. Effect of classical and modified adjuvant CMF-chemotherapy on blood coagulation fibrinolysis in patients with breast cancer. Eur. J. Gynaecol. Oncol., 21: 147-152. PMID: 10843473

Oft, M., K.H. Heider and H. Beug, 1998. TGFbeta signaling is necessary for carcinoma cell invasiveness and metastasis. Cur. Biol., 8: 12431252. PMID: 9822576

Oleksowicz, L., Z. Mrowiec, E. Schwartz, M. Khorshidi and J.P. Dutcher et al., 1995. Characterization of tumor-induced platelet aggregation: The role of immunorelated GPIb and GPIIb/IIIa expression by MCF-7 breast cancer cells. Thromb. Res., 79: 261-274. PMID: 8533122 
Palumbo, J.S., K.E. Talmage, J.V. Massari, C.M. Jeunesse and M.J. Flick et al., 2005. Platelets and fibrin (ogen) increase metastatic potential by impeding natural killer cell-mediated elimination of tumor cells. Blood, 105: 178-185. PMID: 15367435

Prandoni, P., A.W. Lensing, H.R. Buller, A. Cogo and M.H. Prins et al., 1992. Deep-vein thrombosis and the incidence of subsequent symptomatic cancer. N. Eng. J. Med., 327: 1128-1133. PMID: 1528208

Qiu, J., Y. Yu, Y. Fu, F. Ye and X. Xie et al., 2012. Preoperative plasma fibrinogen, platelet count and prognosis in epithelial ovarian cancer. J. Obstet. Gynaecol. Res., 38: 651-657. DOI: 10.1111/j.14470756.2011.01780.x

Rickles, F.R. and A. Falanga, 2001. Molecular basis for the relationship between thrombosis and cancer. Thromb. Res., 102: 215-224. PMID: 11516455

Rocha, E., J.A. Páramo, F.J. Fernández, B. Cuesta and M. Hernández et al., 1989. Clotting activation and impairment of fibrinolysis in malignancy. Thromb. Res., 54: 699-707. DOI: 10.1016/00493848(89)90134-5

Rothwell, P.M., M. Wilson, J.F. Price, J.F. Belch and T.W. Meade et al., 2012. Effect of daily aspirin on risk of cancer metastasis: A study of incident cancers during randomised controlled trials. Lancet, 379: 1591-601. DOI: 10.1016/S01406736(12)60209-8

Ruf, W., N. Yokota and F. Schaffner, 2010 Tissue factor in cancer progression and angiogenesis. Thromb. Res. 2: S36-S38. PMID: 20434002

Sack, G.H., J. Levin and W.R. Bell, 1977. Trousseau's syndrome and other manifestations of chronic disseminated coagulopathy in patients with neoplasms: clinical, pathophysiologic and therapeutic features. Med. Bal., 56: 1-37. PMID: 834136

Shimada, H., G. Oohira, S. Okazumi, H. Matsubara and Y. Nabeya et al., 2004. Thrombocytosis associated with poor prognosis in patients with esophageal carcinoma. J. Am. Coll. Surg., 198: 737-741. PMID: 15110807

Silva, I.D.S., B.L.D. Stavola, C. Pizzi and T.W. Meade, 2010. Circulating levels of coagulation and inflammation markers and cancer risks: Individual participant analysis of data from three long-term cohorts. Int. J. Epidemiol., 39: 699-709. DOI: 10.1093/ije/dyq012

Silverstein, M.D., J.A. Heit, D.N. Mohr, T.M. Petterson and W.M. O'Fallon, 1998. Trends in the incidence of deep vein thrombosis and pulmonary embolism: a 25-year population-based study. Arch Intern. Med., 158: 585-593. PMID: 9521222
Smyth, S.S., D.S. Woulfe, J.I. Weitz, C. Gachet and P.B. Conley et al., 2009. G-protein-coupled receptors as signaling targets for antiplatelet therapy. Arterioscl. Thromb. Vasc. Biol., 29: 449457. PMID: 19023091

Sorensen, H.T., L. Mellemkjaer, F.H. Steffensen, J.H. Olsen and G.L. Nielsen, 1998. The risk of a diagnosis of cancer after primary deep venous thrombosis or pulmonary embolism. N. Eng. J. Med., 338: 1169-1173. PMID: 9554856

Sorensen, H.T., L. Mellemkjaer, J.H. Olsen and J.A. Baron, 2000. Prognosis of cancers associated with venous thromboembolism. N. Engl. J. Med., 343: 1846-1850. PMID: 11117976

Suzuki, K. and T. Hayashi, 2007. Protein C and its inhibitor in malignancy. Semin. Thromb. Hemost, 33: 667-672. PMID: 18000793

Tarek, S. and A.A. Khorana, 2009. New insights into cancer-associated thrombosis. Arterioscler Thromb. Vasc. Biol., 29: 316-320. DOI: 10.1161/ ATVBAHA.108.182196

Tchebiner, J.Z., A. Nutman, B. Boursi, A. Shlomai and T. Sella et al., 2011. Diagnostic and prognostic value of thrombocytosis in admitted medical patients. Am. J. Med. Sci., 342: 395-401. PMID: 21681080

Terraube, V., I. Marx and C.V. Denis, 2007. Role of von Willebrand factor in tumor metastasis. Thromb. Res., 120 2: 64-70. PMID: 18023715

Tesselaar, M.E., F.P. Romijn, I.K.V.D. Linden, F.A. Prins and R.M. Bertina et al., 2007. Microparticle associated tissue factor activity: A link between cancer and thrombosis. J. Thrombosis Haemostasis, 5: 520-527. PMID: 17166244

Tranum, B.L. and A. Haut, 1974. Thrombocytosis: Platelet kinetics in neoplasia. J. Lab. Clin. Med., 84: 615-619. PMID: 4283783

Trikha, M., E. Raso, Y. Cai, Z. Fazakas and S. Paku et al., 1998. Role of alphaII(b)beta3 integrin in prostate cancer metastasis. Prostate, 35: 185-192. PMID: 9582087

Trousseau, A., 1865. Phlegmasia alba dolens. Lectures on clinical medicine, delivered at the Hotel Dieu, (Cliniques médicales de l'Hôtel-Dieu). Paris, 5: 281-332.

Uno, K., S. Homma, T. Satoh, K. Nakanishi and D. Abe et al., 2007. Tissue factor expression as a possible determinant of thromboembolism in ovarian cancer. Br. J. Cancer, 96: 290-295. DOI: 10.1038/sj.bjc.6603552

Varenhorst, E. and B. Risberg, 1981. Effects of estrogen, orchidectomy and cyproterone acetate on tissue fibrinolysis in patients with carcinoma of the prostate. Invest Urol., 18: 355-357. PMID: 7203959 
Varki, A., 2007. Trousseau's syndrome: Multiple definitions and multiple mechanisms. Blood, 110: 1723-1729. DOI: 10.1182/blood-2006-10-053736

Wang, J.G., J.E. Geddings, M.M. Aleman, J.C. Cardenas and P. Chantrathammachart et al., 2012. Tumor-derived tissue factor activates coagulation and enhances thrombosis in a mouse xenograft model of human pancreatic cancer. Blood, 119: 5543-5552. PMID: 22547577

Wang, Z., 2012. Protein S-nitrosylation and cancer. Cancer Lett., 320: 123-129. PMID: 22425962

Wehmeier, A., D. Tschope, J. Esser, C. Menzel and H.K. Nieuwenhuis et al., 1991. Circulating activated platelets in myeloproliferative disorders. Thromb. Res., 61: 271-278. PMID: 1709309

Wilhelmsen, L., K. Svardsudd, K. Korsan-Bengtsen, B. Larsson and L. Welin et al., 1984. Fibrinogen as a risk factor for stroke and myocardial infarction. N. Engl. J. Med., 311: 501-555. PMID: 6749207

Xiao, B., L.L. Ma, S.D. Zhang, C.L. Xiao and J. Lu et al., 2011. Correlation between coagulation function, tumor stage and metastasis in patients with renal cell carcinoma: A retrospective study. Chin. Med. J., 124: 1205-1208. PMID: 21542997

Yapijakis, C., A. Bramos, A.M. Nixon, V. Ragos and E. Vairaktaris, 2012. The interplay between hemostasis and malignancy: The oral cancer paradigm. Anticancer Res., 32: 1791-1800. PMID: 22593463
Yu, J.L., L. May, V. Lhotak, S. Shahrzad and S. Shirasawa et al., 2005. Oncogenic events regulate tissue factor expression in colorectal cancer cells: Implications for tumor progression and angiogenesis. Blood, 105: 1734-1741. PMID: 15494427

Zacharski, L.R., 2011. Controlling cancer growth from within the blood coagulation mechanism. J. Thrombosis Haemostasis, 9: 1804-1806. DOI: 10.1111/j.1538-7836.2011.04447.x

Zacharski, L.R., M.Z. Wojtukiewicz, V Costantini, D.L. Ornstein and V.A. Memoli, 1992. Pathways of coagulation/fibrinolysis activation in malignancy. Semin Thromb. Hemost, 18: 104-106. PMID: 1574711

Zeimet, A.G., C. Marth, E. Müller-Holzner, G. Daxenbichler and O. Dapunt, 1994. Significance of thrombocytosis in patients with epithelial ovarian cancer. Am. J. Obstet. Gynecol., 170: 549-554. PMID: 8116711

Zietek, Z., I. Iwan-Zietek, M. Kotschy, E. Wisniewska and F. Tyloch, 1997a. Activity of antithrombin III in the blood of patients with bladder cancer. Pol. Merkur Lekarski, 2: 268-269. PMID: 9377663

Zietek, Z., I. Iwan-Zietek, M. Kotschy, E. Wisniewska and F. Tyloch 1997b. Antithrombin III activity in blood of patients with renal cancer. Pol. Merkur Lekarski, 2: 191-192. PMID: 10907025 